\title{
Response to: "what is the advantage of using sodium fluorescein during resection of peripheral nerve tumors?"
}

\author{
Matthieu Peyre $^{1,2}$ (D) Michel Kalamarides ${ }^{1,2}$ \\ Received: 29 December 2019 / Accepted: 31 December 2019 /Published online: 6 January 2020 \\ (C) Springer-Verlag GmbH Austria, part of Springer Nature 2020
}

We thank Dr. Vetrano, Nazzi and Acerbi for their comments. We read with great interest their work on the use of fluorescein in peripheral nerve tumor surgery [1] that was not available at the time we drafted our article on a similar topic [2]. We first would like to point out the renowned expertise of the authors in the field of fluorescence-guided neurosurgical oncology [3] and the importance of their study regarding the comparatively high number of tumors analyzed and the variety of histologies.

We agree that fluorescein-guided resection of peripheral nerve sheath tumors is both safe and feasible. Vetrano et al. confirm that fluorescein does not help during the first steps of tumor resection, as continuous free-running and stimulustriggered electromyography remains the best and safest way to identify the entry point inside the pseudocapsule. While their work offers convincing images of the brighter fluorescence of schwannomas compared to adjacent normal nerve fibers after incision of the pseudocapsule, it is difficult to determine if this difference as any impact on the quality of resection and the rate of postoperative complications. As the authors acknowledge, their results are more convincing in the field of plexiform neurofibromas, where fluorescein determined a change in the surgical strategy, although additional studies are needed in both cases to confirm those results.

As schwannomas remain the most frequent peripheral nerve sheath tumor and the only one encountered in schwannomatosis and neurofibromatosis type 2 patients, we

This article is part of the Topical Collection on Peripheral Nerves

Matthieu Peyre

matthieu.peyre@aphp.fr

1 Department of Neurosurgery, Groupe Hospitalier Pitié-Salpêtrière, Sorbonne Universités, 47-83 boulevard de l'Hôpital, 75013, APHP, Paris, France

2 Neurofibromatosis type 2 and Schwannomatosis National Referrence center, Groupe Hospitalier Pitié-Salpêtrière, APHP, Paris, France still question the usefulness of sodium fluorescein in peripheral nerve tumor surgery on a large scale. The cost of this technique does not rest solely upon the fluorophore but on the YELLOW560 microscope filter costing several thousands of euros. This cost must therefore be measured regarding the number of cases operated per year, their level of complexity reflected by the expertise of the surgical center, and the possibility to absorb the cost by expanding the indications in neurosurgical oncology. The evaluation of those techniques by such dedicated teams is therefore essential, and we look forward for their future works in the field.

\section{References}

1. Vetrano IG, Acerbi F, Falco J, Devigili G, Rinaldo S, Messina G, Prada F, D'Ammando A, Nazzi V (2019) Fluorescein-guided removal of peripheral nerve sheath tumors: a preliminary analysis of 20 cases. J Neurosurg

2. Kalamarides M, Bernat I, Peyre M (2019) Extracapsular dissection in peripheral nerve Schwannoma surgery using bright light and fluorescein sodium visualization: case series. Acta Neurochir. (Wien)

3. Acerbi F, Broggi M, Schebesch K et al (2018) Fluorescein-guided surgery for resection of high-grade Gliomas: a multicentric prospective phase II study (FLUOGLIO). Clin Cancer Res 24(1):52-61

Publisher's note Springer Nature remains neutral with regard to jurisdictional claims in published maps and institutional affiliations. 